\title{
Novel interactions between alien pathogens and native plants increase plant-pathogen network connectance and decrease specialization
}

\author{
Jennifer L. Bufford ${ }^{1}$ (D) | Philip E. Hulme ${ }^{1}$ (D) | Benjamin A. Sikes ${ }^{2}$ | Jerry A. Cooper ${ }^{3}$ | \\ Peter R. Johnston ${ }^{4}$ | Richard P. Duncan ${ }^{1,5}$
}

${ }^{1}$ Bio-Protection Research Centre, Lincoln University, Lincoln, New Zealand

${ }^{2}$ Department of Ecology and Evolutionary Biology and Kansas Biological

Survey, University of Kansas, Lawrence, KS, USA

${ }^{3}$ Landcare Research, Lincoln, New Zealand

${ }^{4}$ Landcare Research, Auckland Mail Centre, Auckland, New Zealand

${ }^{5}$ Institute for Applied Ecology, University of Canberra, Canberra, ACT, Australia

\section{Correspondence}

Jennifer L. Bufford

Email: jennifer.bufford@lincoln.ac.nz

Funding information

Tertiary Education Commission

Handling Editor: Eric Allan

\section{Abstract}

1. Alien plant pathogens are a threat to native plants and are increasingly integrating into native plant-pathogen networks, but how these novel plant-pathogen networks are structured remains unclear. Theory predicts that novel antagonists are likely to be generalists, resulting in interaction networks with greater nestedness as well as lower modularity and specialization than native networks.

2. We tested these predictions by quantifying associations between native plants and their native and alien pathogens using a comprehensive database of plantfungal associations in New Zealand. We compared the host ranges of alien and native pathogens and the structure of native and alien pathogen subnetworks.

3. As predicted, alien pathogens associated with a greater number and diversity of native plant host species than native pathogens. The alien pathogen subnetwork was more nested and connected, but less modular and less specialized than the native pathogen subnetwork, consistent with expectations for novel interactions. Alien pathogens altered the overall native plant-pathogen network structure, making the full network more connected and less specialized than the native network. Modules in the native and alien subnetworks were clustered by host phylogeny but did not show a clear signal associated with host habitat or region.

4. Synthesis. Our study provides some of the first empirical insights into the structure of novel plant-pathogen networks and the changes that occur when alien pathogens invade a native network. Because alien pathogens interacted with more hosts than native pathogens, alien pathogens have an increased risk of adverse indirect effects, including pathogen spillover, host jumps and network destabilization.

\section{KEYWORDS}

emerging diseases, exotic, fungal pathogens, graph theory, host range, invasive species, nonnative, oomycetes 


\section{1 | INTRODUCTION}

Despite the major role plant diseases play in ecosystems and the increasing global movement of pathogens (Anderson et al., 2004; Bebber, Holmes, \& Gurr, 2014; Smith, Sax, \& Lafferty, 2006), we have a limited understanding of the community dynamics associated with novel pathogens. The invasion of alien pathogens into native plant-pathogen interaction networks provides an opportunity to better understand these dynamics (Burdon \& Thrall, 2013; Parker \& Gilbert, 2004; Young, Parker, Gilbert, Guerra, \& Nunn, 2017). By contrasting native and alien plant-pathogen interactions and understanding how alien pathogens integrate into and potentially alter the structure of existing plant-pathogen interaction networks, we can gain insights into network assembly and change over time, and the potential consequences of alien pathogen invasions.

Successful alien pathogens are expected to have broad host ranges because more generalist pathogens are more likely to encounter a suitable host, thus increasing their chances of establishing in a new region (Dickie, Bufford, et al., 2017; Parker \& Gilbert, 2004; Philibert et al., 2011). Pathogens with broad host ranges are also more likely to colonize novel hosts, particularly those that are closely related to hosts from the pathogen's native range, as host defences, and therefore host susceptibility, are often phylogenetically conserved (Barrett \& Heil, 2012; Bufford et al., 2016; Flory \& Clay, 2013; Parker et al., 2015). The host range of alien pathogens will in turn affect the impact they have and the role they play in interaction networks. Although the role of generalist alien plants and insects has been well-documented in mutualist plant-pollinator networks (Lopezaraiza-Mikel, Hayes, Whalley, \& Memmott, 2007; Russo, Memmott, Montoya, Shea, \& Buckley, 2014; Stouffer, Cirtwill, \& Bascompte, 2014; Valdovinos, Ramos-Jiliberto, Flores, Espinoza, \& López, 2009), very few studies have considered antagonists, particularly alien plant pathogens (Médoc et al., 2017; Vacher, Daudin, Piou, \& DesprezLoustau, 2010).

As a consequence of broad host ranges and opportunistic colonization of naïve hosts, alien pathogens may exhibit substantial overlap in native hosts resulting in a network with a strongly nested structure (Andreazzi, Thompson, \& Guimarães Jr, 2017), moderate connectance and linkage density, and low modularity (Table 1). By contrast, networks with a long evolutionary history, such as native plant-native pathogen associations, should exhibit greater specialization, particularly if evolutionary arms-races led pathogens to specialize on the most susceptible host species. This should reduce host overlap between native pathogens and lead to a more modular and specialized network structure with lower nestedness (Andreazzi et al., 2017; Lewinsohn \& Prado, 2006).

Network modules are groups of species that interact more with each other than with other species in the broader network. Identifying modules and understanding their composition can provide insight into why and how host plants share pathogens (Lewinsohn \& Prado, 2006). In plant-pathogen networks, modules are often correlated with host phylogeny when groups of related plant species tend to be colonized by a shared suite of pathogens

TAB LE 1 A brief description of common metrics that describe network architecture and function and the predicted relative values of these metrics in networks of novel interactions, as compared with the metrics in non-novel networks (Andreazzi et al., 2017)

\begin{tabular}{|c|c|c|c|}
\hline Network metric & Description & $\begin{array}{l}\text { Predicted for } \\
\text { novel networks }\end{array}$ & Proposed mechanism \\
\hline Linkage density & $\begin{array}{l}\text { Weighted mean number of interactions per } \\
\text { species }\end{array}$ & Increase & $\begin{array}{l}\text { Successful alien pathogens are generalists, with a } \\
\text { greater number of interactions per species }\end{array}$ \\
\hline Connectance & $\begin{array}{l}\text { Proportion of interactions that actually } \\
\text { occur relative to the number of interac- } \\
\text { tions possible if every pathogen colonized } \\
\text { every host species }\end{array}$ & Increase & $\begin{array}{l}\text { In novel systems, generalist pathogens take advantage } \\
\text { of weak naïve plant defences, thus increasing the } \\
\text { number of associations that form out of all possible } \\
\text { associations when compared to non-novel systems, } \\
\text { where plant defences exclude many pathogens and } \\
\text { pathogens specialize on different plant species }\end{array}$ \\
\hline Nestedness & $\begin{array}{l}\text { The tendency of specialists to interact } \\
\text { with generalists }\end{array}$ & Increase & $\begin{array}{l}\text { Novel pathogens include species with a range of host } \\
\text { specificities, while abundant or poorly-defended } \\
\text { naïve plants may serve as hosts for a diversity of } \\
\text { pathogens. This results in a nested structure where } \\
\text { generalist pathogens interact with a wide diversity of } \\
\text { hosts, while specialists tend to interact with a subset } \\
\text { of these hosts }\end{array}$ \\
\hline Modularity & $\begin{array}{l}\text { The tendency of groups of species to } \\
\text { interact with each other more than with } \\
\text { the rest of the network }\end{array}$ & Decrease & $\begin{array}{l}\text { Pathogens tend to infect groups of co-occurring or re- } \\
\text { lated plants, creating strong modularity in non-novel } \\
\text { systems. Generalist novel pathogens, however, may } \\
\text { interact with a greater diversity of species or across } \\
\text { habitats, decreasing modularity }\end{array}$ \\
\hline Specialization $\left(\mathrm{H}_{2}^{\prime}\right)$ & $\begin{array}{l}\text { A network-level measure of the diversity } \\
\text { of partners using Shannon entropy }\end{array}$ & Decrease & $\begin{array}{l}\text { Generalist pathogens infect naïve hosts with weak } \\
\text { defences against the novel pathogen, resulting in a } \\
\text { high diversity of partners }\end{array}$ \\
\hline
\end{tabular}


(Elias, Fontaine, \& van Veen, 2013; Vacher, Piou, \& Desprez-Loustau, 2008). We expect module composition in novel native plant-alien pathogen networks to show a strong signal of host phylogeny if alien pathogens are pre-adapted to colonize novel hosts in the new range that are closely related to hosts from the pathogen's native range (Bufford et al., 2016; Gilbert, Magarey, Suiter, \& Webb, 2012; Parker et al., 2015). However, over time pathogens may also shift to colonize co-occurring, but less closely related, plant species (Parker \& Gilbert, 2004). Therefore, in networks with a long evolutionary history, such as native plant-pathogen networks, module composition could reflect both host phylogeny and shared habitat or geographical region. Habitat and region have been found to influence module composition in island seed dispersal networks (Nogales et al., 2016) and native plant co-occurrence networks (Hui et al., 2013), but not in a plant-pathogen network (Vacher et al., 2008).

The arrival and integration of alien pathogens into native plantpathogen networks provides an opportunity to test these predictions about novel pathogen interactions and how they alter network structure. Using a comprehensive database of plant-pathogen associations in New Zealand (Johnston, Weir, \& Cooper, 2017), we examined: Q1) whether alien pathogens colonize more native host plant species or a more phylogenetically diverse set of hosts than native pathogens; Q2) whether the alien pathogen-native plant subnetwork differs in structural characteristics from the native pathogen-native plant subnetwork, as predicted for novel interactions (Table 1), and whether any differences are strong enough to substantially alter the full pathogen-native plant network; and Q3) whether modules within the alien and native pathogen networks reflect shared host phylogeny, habitat or geographical region. We were able to compare native and alien pathogens in native plant networks to address these questions because New Zealand's isolation and extensive records since European colonization allowed native and alien pathogens to be distinguished, which is rarely done, and provided a volume and resolution of data rarely available for plant-pathogen interactions (Johnston et al., 2017; Sikes et al., 2018).

\section{2 | MATERIALS AND METHODS}

\section{1 | Plant-pathogen associations recorded in New Zealand}

We compiled a database of plant-pathogen associations recorded in New Zealand between 1847 and 2012. Each record was an observation of a plant-fungal association and included host plant identity, fungus identity, the year in which the association was recorded and the source of the record. The data came primarily from the NZFungi2 database (Johnston et al., 2017; Landcare Research, 2014), with additional records from the HerbIMI database (Kew Royal Botanical Gardens, 2012). Together, these data include the large majority of plant-fungal records known from New Zealand (Johnston et al., 2017). Records were derived from direct observations (e.g. cultures) and from published records of observations. We used taxonomic databases to standardize taxonomic names prior to analysis and removed hybrids and records with misapplied or subsequently split names that could not be resolved (Bufford et al., 2016). Given that each record should represent a unique observation of a specific plant-fungal interaction, we removed records likely to be duplicates (e.g. arising from published compilations; Table S1). We retained only records where both the pathogen and the host were identified to at least the species level and taxa identified to the infraspecific level were pooled at the species level, as this is the taxonomic level at which most associations were recorded. Analysing pathogens at the species level, rather than at the infraspecific level, might be expected to increase pathogen host range, but we have no reason to expect a priori a differential effect on native or alien pathogens.

The database was filtered to include only pathogenic fungi, oomycetes and plasmodiophorids, and their associated native plant host species. We focused exclusively on native plant hosts because this allowed us to compare novel (alien pathogen-native plant) and non-novel (native pathogen-native plant) associations. Whether associations between alien plants and alien pathogens are novel depends on whether they interacted in their native ranges and that information was generally not available. Therefore, novel and non-novel associations could not clearly be distinguished for host plants alien to New Zealand. Because the full database included fungi from a variety of functional groups (e.g. mycorrhizae, saprotrophs, etc.), we restricted the database to fungi classified as pathogens at the genus level by expert opinion, based on the presence of pathogenic species within the genus in New Zealand. While the data record pathogen presence, not disease symptoms or severity, most records come from observations of symptomatic plants, meaning the species in our database are likely to be pathogenic on the hosts recorded. However, it can be difficult to distinguish pathogenic and saprobic fungi and the trophic relationships between native fungi and their hosts are not always clear (Gadgil, 2005). The native or alien status of plant and pathogen species in New Zealand was assigned using national databases (Allan Herbarium, 2015; Landcare Research, 2014), for which status has been determined by expert opinion using the best available evidence, including the spatiotemporal distribution of records and the hosts and plant communities each pathogen was recorded in. Pathogens with an uncertain status in New Zealand were excluded. We also removed some prominent fungal species that are difficult to define taxonomically, as these could lead to an overestimate of the number of associations ( $n=10$ pathogen species; Table S2). We excluded records from the subantarctic islands, the Kermadec and Three Kings Islands and from the Chatham Islands, as these are geographically distant and ecologically distinct from mainland New Zealand, where most interactions were recorded. Poor sampling of rare species can underestimate the pathogen range of a host and lead to overestimates of specialization and nestedness, as well as underestimates of connectance (Blüthgen, Fründ, Vázquez, \& Menzel, 2008; Morris, Gripenberg, Lewis, \& Roslin, 2014). We mitigated sampling effects by only including native plant species with at least 10 records in the database, irrespective of whether the records were with native or alien pathogens. As a result, our analysis included 149 native plant hosts ( $n=3,159$ records) because there were insufficient records available for most of the 2413 native vascular 
plant species in New Zealand (de Lange \& Rolfe, 2010). Of the host species included, 115 are considered endemic to New Zealand and the families ( $n=52$ ) most commonly represented were the Asteraceae (11\% of species), Cyperaceae (11\%) and Poaceae (9\%). The high level of endemism in our database confirms that associations between alien pathogens and native plants are expected to be novel. Native fungi in our network interacted almost exclusively with native hosts ( $98 \pm 0.5 \%$ native hosts). In contrast, alien pathogens interacted with both native hosts ( $63 \pm 3 \%$ native hosts) and 62 species of naturalized alien plants considered environmental weeds in New Zealand (Howell, 2008). Of the 365 pathogens included in the database, most were above-ground pathogens $(n=309)$. In particular, native rusts are well-documented (McKenzie, 1998) and of the 35 orders included, the orders Pucciniales (24\%) and Capnodiales (14\%) were most commonly represented.

Database processing and all analyses were performed in $\mathrm{R}(\mathrm{R}$ Core Team, 2017). We modified code from the packages 'TAXIZE' (Chamberlain \& Szöcs, 2013) and 'TAXONSTAND' (Cayuela, Granzow-de la Cerda, Albuquerque, \& Golicher, 2012) to access the global taxonomic databases (originally accessed June 2015) with subsequent updates made manually as necessary.

\subsection{Network construction}

We constructed bipartite networks of native plants and their pathogens using the number of times the association was recorded in the database as the edge weight. The number of records was used to weight the network because it was considered to represent the frequency of interactions, although it may also be confounded with sampling effort. To evaluate this assumption, we repeated the analyses on an unweighted network. To test our predictions, we compared two subnetworks: native plants with only native pathogens, and native plants with only alien pathogens, accounting for subnetwork size. We also compared the full network, comprising all native plants and all recorded pathogens, with the native subnetwork to examine how the inclusion of alien pathogens altered the overall network structure. A complete list of the pathogens (Table S3) and plant hosts (Table S4) included in the analyses is in the supporting information.

\section{3 | Analyses}

\subsection{1 | Are alien pathogens more generalist (Q1)?}

To explore the differences between native and alien pathogen species, we compared the number and phylogenetic breadth of host species. We calculated the number of native hosts for each pathogen from the network and modelled host number as a function of pathogen status in New Zealand (native or alien). We did this by fitting a Poisson generalized linear mixed-effects model, which included the total number of records in the network for each pathogen (log-transformed) as a fixed effect covariate to account for sampling effort, and pathogen order as a random effect to account for phylogenetic similarities. We additionally tested whether the log-transformed number of records differed between native and alien pathogens using a
Welch two-sampled $t$-test. To test for differences between alien and native pathogens in the phylogenetic breadth of their host range, we calculated the phylogenetic distances between all possible plant host pairs for each pathogen (Figure S1) using the dated phylogenetic supertree R2G2_20140601 from Parker et al. (2015) and the program phylomatic (Webb \& Donoghue, 2005). Where pathogens only had a single host, the phylogenetic distance was set to zero. Mean, median and maximum pairwise phylogenetic distance of a pathogen's hosts were all highly correlated $(r>0.9)$. Therefore, we modelled median pairwise phylogenetic distance as a function of pathogen status in New Zealand and log-transformed total number of native hosts using a linear mixed-effects model, with pathogen order as a random effect. Number of native hosts was included in the model to account for any increase in phylogenetic distance due simply to sampling effects. For mixed-effects models of host number and phylogenetic host range, we examined model diagnostics, including testing for overdispersion, and calculated significance using $95 \%$ confidence intervals from parametric bootstrap and likelihood ratio tests (Bolker et al., 2009). We also examined the effect of any influential points on the model results. All models and bootstrapping were implemented in the package 'LME4' (Bates, Maechler, Bolker, \& Walker, 2014). For each model, we calculated the marginal and conditional $R^{2}$ values, where marginal $R^{2}$ values show the variation explained by the fixed effects and conditional $R^{2}$ shows the variation explained by both fixed and random effects (Nakagawa \& Schielzeth, 2013).

\subsubsection{Do novel interactions alter networks (Q2)?}

To test for the predicted effects of novelty on network structure, we compared the structure of the native pathogen subnetwork with the novel alien pathogen subnetwork. For each subnetwork, we calculated connectance, linkage density (Bersier, BanašekRichter, \& Cattin, 2002), nestedness, measured as weighted NODF (Almeida-Neto, Guimarães Jr, Loyota, \& Ulrich, 2008) and specialization ( $\mathrm{H}_{2}^{\prime}$; Blüthgen, Menzel, \& Blüthgen, 2006) using the package 'BIPARTITE' (Dormann, Fruend, Blüthgen, \& Gruber, 2009; Dormann, Gruber, \& Fruend, 2008), while modularity (Clauset, Newman, \& Moore, 2004) was calculated using the package 'IGRAPH' (Csardi \& Nepusz, 2006) with clusters computed following Blondel, Guillaume, Lambiotte, and Lefebvre (2008). Connectance and linkage density assess how many interactions occur across the network, while nestedness, specialization and modularity describe how interactions are structured within the network. To assess the significance of differences in these metrics between the two subnetworks, we simulated 1000 full networks. We considered the host as the sampling unit and therefore maintained the number of pathogens and distribution of records (edge weights) for each host but randomized the identity of the pathogens associated with each host. Shuffling pathogen identities generated networks under a null hypothesis of random association while maintaining the original matrix size and structure. We simulated differences under a null model that maintained the original matrix sizes to eliminate differences in network metrics that might be due to matrix size 
alone (Blüthgen et al., 2008; Morris et al., 2014). To assess the statistical significance of differences between observed subnetwork metrics, we compared the observed and simulated differences between the alien and native pathogen subnetworks and counted the number of simulations in which the simulated difference was more extreme than the observed difference, divided by the total number of simulations. Similarly, to assess how alien pathogens integrated into the full network structure, we compared simulated and observed differences between the full network and the native subnetwork as described above. These analyses were repeated for unweighted networks.

\subsection{3 | Are modules determined by phylogeny, habitat or region (Q3)?}

To investigate module composition within the network, we examined modules in the alien and native subnetworks, focusing on the largest connected component in each subnetwork, excluding modules formed around peripheral, unconnected clusters of nodes. The largest component of the alien subnetwork included 52 hosts, 67 pathogens and 271 records, and the largest component of the native subnetwork included 58 hosts and 126 pathogens from 1295 records. We classified the hosts in these components by habitat (forest, alpine, coastal, open/disturbed, riparian/wetland) and by geographic ecoregion (10 regions determined by climate and location, Figure S2) in New Zealand. Plant habitats and distributions were classified primarily using the New Zealand Plant Conservation Network (www.nzpcn.org.nz), but also NatureWatch (www.inaturalist.org), TERRAIN (www.citscihub.nz), and general web searches as needed. We used a Mantel test to evaluate the correlation between log-transformed phylogenetic distance and a true/false matrix indicating shared module occupancy. We then conducted a partial Mantel test to evaluate the correlation between shared module occupancy and the proportion of shared habitats or regions out of those occupied by either species, while controlling for log-transformed phylogenetic distance (Oksanen et al., 2013; Quinn \& Keough, 2002).

\section{3 | RESULTS}

\subsection{Are alien pathogens more generalist (Q1)?}

Alien pathogens were recorded on more native plant species than native pathogens when the number of records was taken into account (Figure 1a; $p=.011$ ). Although alien pathogens had, on average, fewer records per species $(3.7 \pm 0.51$, mean $\pm S E$ ) than native pathogens $(10.8 \pm 0.76, p<.0001)$, they were recorded on a similar number of host species (aliens $1.7 \pm 0.20$, natives $1.63 \pm 0.098$ mean hosts $\pm S E$ ), and therefore had a higher number of hosts per species than expected. Independent of native status or number of records, pathogens in the orders Agaricales, Hypocreales, and Peronosporales had more hosts, while pathogens in the order Pucciniales had fewer hosts than average (Figure S3). The model had moderate explanatory power (marginal $R^{2}=.2$, conditional $R^{2}=.3$ ).

Alien pathogens colonized hosts with greater median pairwise phylogenetic distances (76 $\pm 15 \mathrm{myr}$ ) than native pathogens did (35 \pm 7 myr). Irrespective of origin, pathogens with a greater number of hosts also colonized a broader phylogenetic range of hosts (Figure 1b). The model had moderate explanatory power (marginal $R^{2}=.37$; conditional $R^{2}=.42$ ). Pathogens in the order Pythiales had greater median host pairwise phylogenetic distance and pathogens in the order Pucciniales had lower host distance (Figure S4).

\subsection{Do novel interactions alter networks (Q2)?}

The alien subnetwork had higher connectance and linkage density, was more nested, and had lower modularity and specialization than the native subnetwork (Figure 2). These differences were significantly greater than those expected under null model simulations (Table 2) and results were similar in unweighted networks
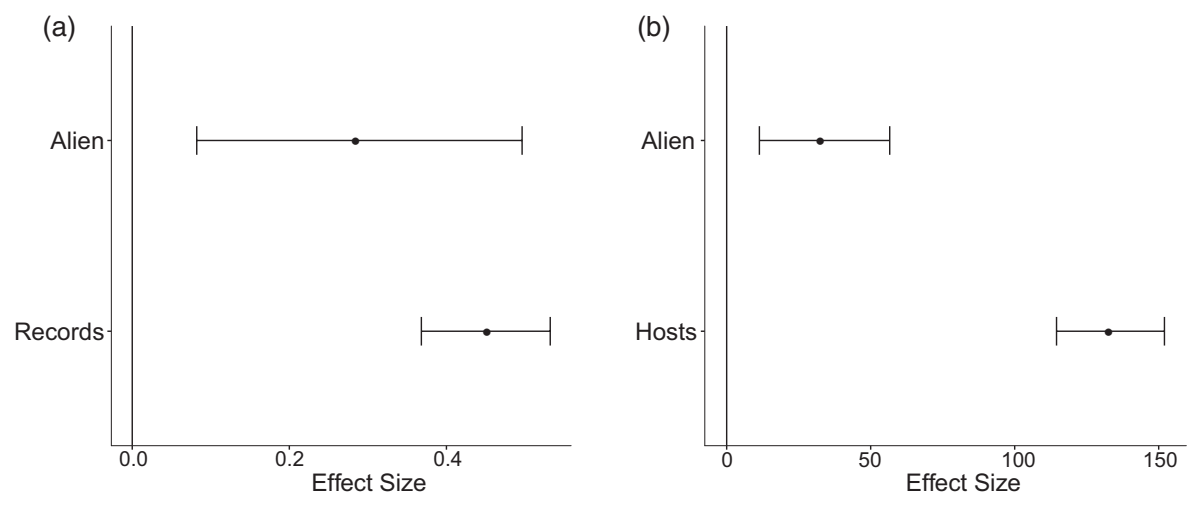

FIGURE 1 Coefficient estimates (effect size) from (a) a Poisson generalized linear mixed-effects model explaining the number of native host species and (b) a linear mixed-effects model of the median pairwise phylogenetic distance between native host species of fungal pathogens in New Zealand. The explanatory variables included pathogen status in New Zealand (alien or native) with pathogen order as a random effect and (a) the log number of records for each pathogen in the database or (b) the log number of host species as fixed effects. Effect sizes are relative to a native pathogen. Error bars represent bootstrapped $95 \%$ confidence intervals 


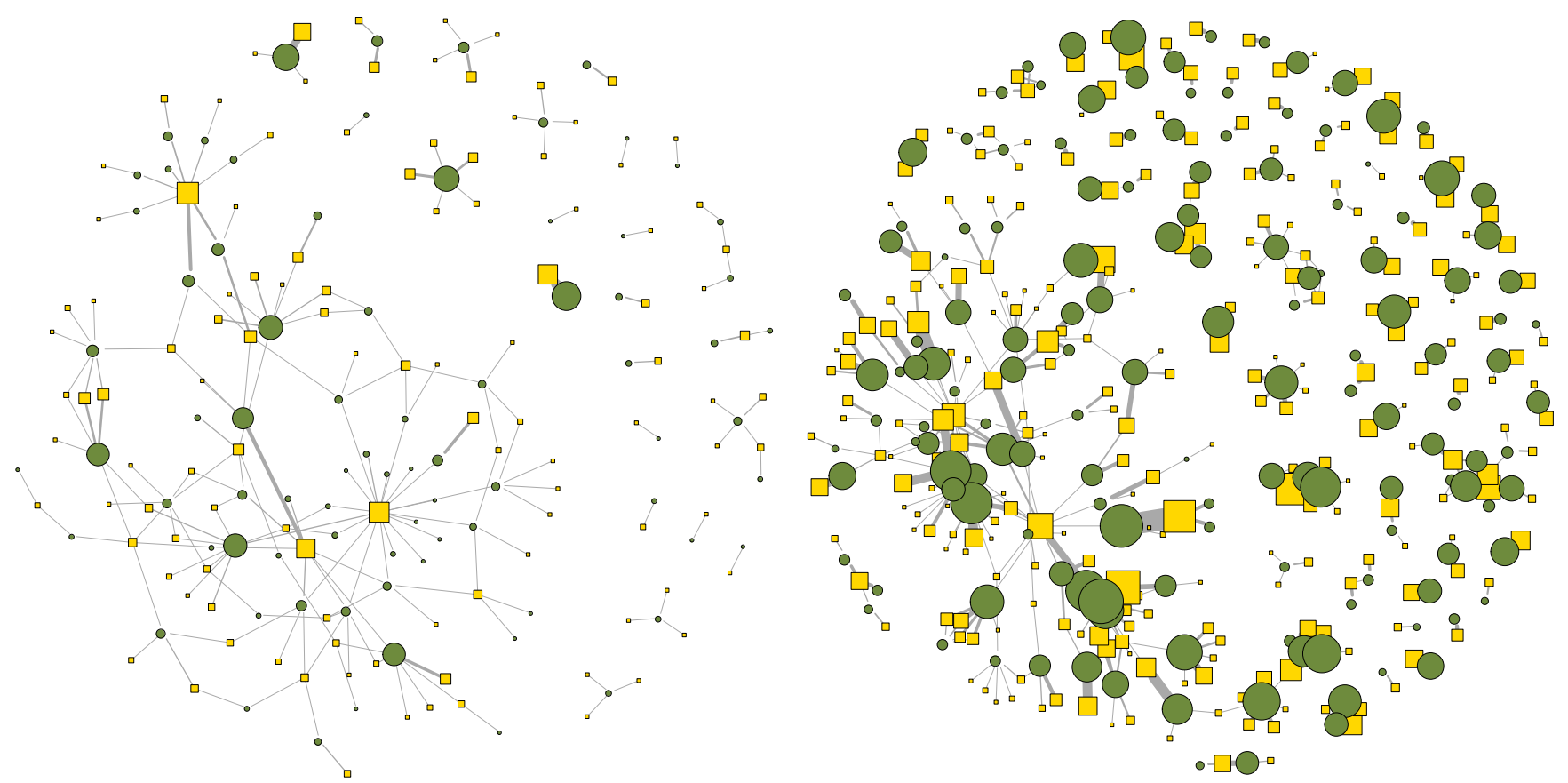

FIGURE 2 Bipartite subnetworks of native New Zealand plant species and their alien (left) and native (right) pathogen species. Each node represents a species, with plants shown as green circles, pathogens shown as yellow squares, and lines connecting pathogens to plants they have been recorded on. The size of each node is proportional to the square root of the number of records for that species, the width of the link is proportional to the number of records of that association, and the position of nodes is determined by the Fruchterman-Reingold algorithm. In the alien subnetwork, the pathogens that connected to the most hosts were Phytophthora cinnamomi (20 hosts), Fusarium solani (8 hosts) and Claviceps purpurea (8 hosts), while the most connected pathogens in the native subnetwork were Armillaria novae-zelandiae (15 hosts) and Ilyonectria coprosmae (14 hosts) [Colour figure can be viewed at wileyonlinelibrary.com]

(Table S5). Of the 78 native host species within the alien pathogen subnetwork, only 4 (5\%) were unique to the alien pathogen subnetwork, while 71 hosts were unique to the native subnetwork. Endemic plants were not more abundant in this set of unique hosts, but grasses were rare. In the native and alien subnetworks respectively, 1 to $2 \%$ of all possible links were present (connectance) and species associated with an average weighted diversity of 2 or 3 other species (linkage density). The observed associations showed a high level of specialization and most interactions occurred within modules in both subnetworks (modularity; Table 2). Specialists tended to interact with generalists in the alien subnetwork, but this was not true in the native subnetwork, which had low nestedness.

The full network of native plants and their pathogens in New Zealand included 149 native plant hosts, 115 of which are endemic to New Zealand, and 365 pathogens (Table 2; Figure S5). In the full network, aliens represented $31 \%$ of the total pathogen richness and formed associations with $52 \%$ of the native hosts (Table 2). When the full network was compared to the native subnetwork, the full
TABLE 2 Description and structure of weighted bipartite plant-pathogen networks. The full network includes native New Zealand plants and their pathogens, both alien and native, while the two subnetworks include only alien or native pathogens. The final two columns show the differences in network measures between networks, with significance calculated by comparing observed and simulated differences

\begin{tabular}{|llllll|} 
& $\begin{array}{l}\text { Full } \\
\text { network }\end{array}$ & $\begin{array}{l}\text { Alien } \\
\text { subnetwork }\end{array}$ & $\begin{array}{l}\text { Native } \\
\text { subnetwork }\end{array}$ & $\begin{array}{l}\text { Alien vs. } \\
\text { native }\end{array}$ & $\begin{array}{l}\text { Full vs. } \\
\text { native }\end{array}$ \\
\hline Hosts & 149 & 78 & 145 & \\
\hline Pathogens & 365 & 112 & 253 & & \\
\hline Records & 3,159 & 415 & 2,744 & & \\
\hline $\begin{array}{l}\text { Connectance } \\
\text { Linkage density } \\
\text { (weighted links/ }\end{array}$ & 0.011 & 0.022 & 0.011 & $0.011^{* * *}$ & -0.00008 \\
\hline node) & 2.8 & 3.3 & 2.28 & $1.0^{* * *}$ & $0.524^{* *}$ \\
\hline $\begin{array}{c}\text { Nestedness } \\
\text { (weighted NODF) }\end{array}$ & 0.494 & 0.980 & 0.457 & $0.523^{* *}$ & 0.037 \\
\hline $\begin{array}{c}\text { Specialization (H') } \\
\text { (w) }\end{array}$ & 0.819 & 0.670 & 0.850 & $-0.180^{* * *}$ & $-0.031^{* *}$ \\
\hline Modularity & 0.826 & 0.795 & 0.888 & $-0.093^{* * *}$ & -0.061 \\
\hline
\end{tabular}

${ }^{* * *} p \leq .001$

${ }^{* *} p \leq .01$. 
network had greater linkage density and slightly lower specialization, while nestedness and modularity were not significantly different (Table 2). Some alien fungi (e.g. Claviceps purpurea) connected native hosts (a suite of grasses) that were not otherwise connected by native pathogens (Figure S5). The difference in connectance between these two networks was smaller than expected by chance. Results using an unweighted network were similar, except the unweighted network showed a significantly greater nestedness (NODF) in the full network (Table S5).

\section{3 | Are modules determined by phylogeny, habitat or region (Q3)?}

The largest connected component of the alien subnetwork was divided into 8 modules and shared module occupancy was correlated with decreasing phylogenetic distance $(r=-.14, p=.001)$. The probability that two hosts shared a module $(n=13)$ in the native subnetwork was more strongly correlated with phylogenetic distance $(r=-.28, p=.001$, Figure 3 ) than in the alien subnetwork. Shared habitats and regions were not correlated with shared modules in either subnetwork, when phylogenetic distance was accounted for $(r<.04, p \geq .2)$.

\section{4 | DISCUSSION}

As expected, alien fungal pathogens were more generalist than native pathogens on native New Zealand plant host species, which resulted in different plant-pathogen network structures. Alien pathogens colonised more host species and a broader phylogenetic diversity of hosts than native pathogens on average. Consequently, the alien pathogen subnetwork was more nested

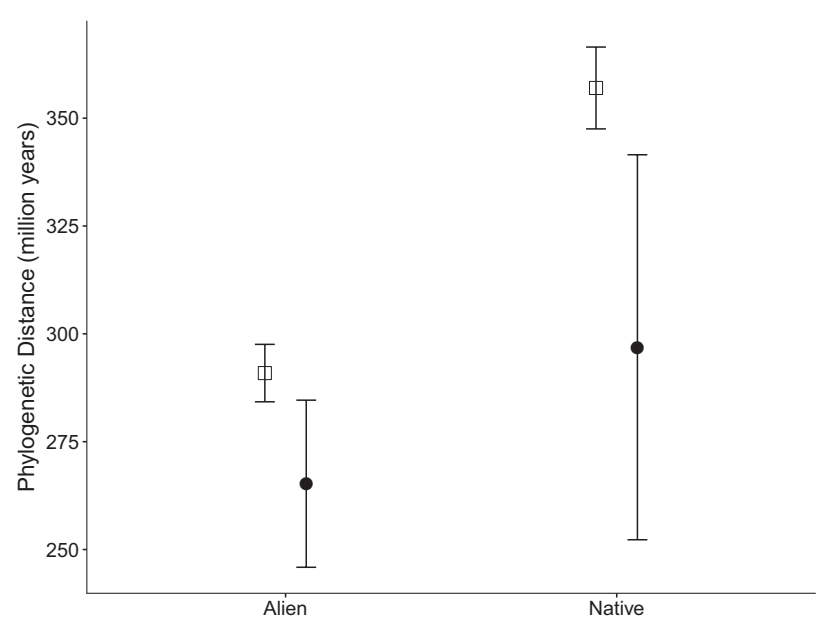

FIGURE 3 Mean phylogenetic distance between plant host species that do (closed circles) or do not (open squares) share a module within the largest connected component of the alien and native pathogen subnetworks in a network of pathogen associations with native plant hosts in New Zealand. Error bars represent $95 \%$ confidence intervals and more connected, but less modular and less specialized than the native pathogen subnetwork. These differences were enough to increase linkage density and decrease specialization in the full plant-pathogen network when alien pathogens were incorporated. Within both the native and alien pathogen subnetworks, modules in the largest connected component of the subnetwork reflected host phylogeny, but not shared host habitats or geographic regions, suggesting that phylogenetic conservation of plant hosts for both native and alien pathogens is a major driver of network structure.

\subsection{Aliens are more generalist (Q1) and novel interactions alter network topography (Q2)}

The broader native host range of alien pathogens in New Zealand is consistent with patterns detected in pathogens of woody plants in Europe (Vacher et al., 2010) and grasslands in California (Parker et al., 2015), and the subsequent changes to the interaction network structure match those predicted, suggesting these may be general outcomes of alien pathogen invasion (Table 1). Furthermore, because most native pathogens were restricted to native hosts, while alien pathogens also colonized alien hosts, our estimates of alien host ranges are conservative. Because alien pathogens colonized more hosts than native pathogens, this led to greater connectance and linkage density in the alien subnetwork. These differences are strong enough to alter the full network structure, increasing linkage density and minimizing the effect of increased network size on connectance (Blüthgen et al., 2008), as aliens represented a third of the total pathogen diversity. However, connectance in our networks was low, even for high-intimacy antagonistic networks (Pires \& Guimarães, 2012). This may partly be a result of the broad geographical scale covered by our national network, because some species in the network do not co-occur at a local scale and therefore cannot form links.

By contrast, the native network was highly specialized and modular, consistent with theoretical expectations for plants and pathogens with a long shared evolutionary history (Andreazzi et al., 2017; Lewinsohn \& Prado, 2006). Modularity in our native network was higher than in other published plant-pathogen networks (Barrett, Encinas-Viso, Burdon, \& Thrall, 2015) and many other high-intimacy networks (Pires \& Guimarães Jr, 2012). Specialization was higher than that recorded for host-parasitoid interactions (Morris et al., 2014). Theory predicts that high modularity and specialization occur as native pathogens specialize on their native plant hosts, which is consistent with our findings (Andreazzi et al., 2017) and should stabilize the network (Thébault \& Fontaine, 2010). Studies of plant-fungal associations in New Zealand and plant co-occurrences in Europe have similarly found that native associations are more modular than alien associations (Dickie, Cooper, Bufford, Hulme, \& Bates, 2017; Hui et al., 2013). However, when alien pathogens were incorporated into the native plant-pathogen network, modularity did not change, perhaps because aliens integrated into the existing modules created by native plant-pathogen interactions (Vacher et al., 2010). 


\section{2 | Modules reflect phylogeny, not shared ecology (Q3)}

Modules in both the native and alien subnetworks were largely determined by host phylogenetic similarity. Host range in pathogens is often phylogenetically determined and our analysis found a strong phylogenetic influence, particularly in the native subnetwork, which is consistent with the more phylogenetically restricted host range of native pathogens. Our analysis did not detect a habitat influence on module composition, however. The lack of a habitat or geographical signal in network modules may be partly explained by the spatial scale and the predominance of above-ground pathogens in the network (e.g. rusts), which may be more likely to disperse across habitats or regions (Brown \& Hovmøller, 2002; Viljanen-Rollinson \& Cromey, 2002). Other studies have likewise found a strong effect of host plant phylogeny, but weak or no effect of habitat on modules in plant-pathogen networks in Europe (Vacher et al., 2010, 2008).

\section{3 | Ecological implications of novel interactions and network shifts}

Alien pathogens colonize more hosts, increasing linkage density in the network, which has the potential to promote pathogen spillover onto co-occurring host species and impact plant population and community dynamics (Flory \& Clay, 2013; Power \& Mitchell, 2004; Young et al., 2017). Links in a plant-pathogen network can reveal which pathogens are mostly likely to spillover and module structure can identify hosts that are most at risk. Where specialization is lower, as in the network that included alien pathogens, there is more opportunity for spillover because there is a greater diversity of interacting pairs (Power \& Mitchell, 2004). Measuring host range and spillover can highlight biosecurity risks and the potential impact of alien and emerging pathogens (Anderson et al., 2004; Fisher et al., 2012). Alien plant hosts could also increase spillover, for example by functioning as disease reservoirs. Constructing local-scale networks of co-occurring species, or weighting networks by the intensity of interactions (i.e. virulence) could further refine predictions of spillover, but to date these data are not available for many pathogen associations (Parker \& Gilbert, 2004; Young et al., 2017).

Network structure may also indicate the stability of the current community's species composition and interspecific interactions (Thébault \& Fontaine, 2010). More connected networks are predicted to be less stable (Thébault \& Fontaine, 2010), such that the integration of alien pathogens into the network may increase the risk of local extinctions (de Castro \& Bolker, 2005b; Fisher et al., 2012; Young et al., 2017). Less specialized pathogens with a greater host range, and therefore greater linkage density, should be more prone to invade and more likely to cause local host extinctions (de Castro \& Bolker, 2005b). This is especially concerning where novel alien pathogens may have greater impacts on naïve hosts than native pathogens (de Castro \& Bolker, 2005a; Fisher et al., 2012; Smith et al., 2006). How alien pathogens integrate into the network may also reveal evidence for competition between pathogen species, which is still poorly understood (DesprezLoustau et al., 2007). Given that aliens represented $31 \%$ of the total pathogen richness in the full network and formed associations with $52 \%$ of the plant host species, our results suggest that native pathogens do not strongly limit the integration of alien pathogens into the network.

Over time generalist pathogens should evolve to become more specialized on their hosts (Andreazzi et al., 2017) and theory has predicted that virulence should also decline, although the evidence is weak (Gilbert \& Parker, 2010; Parker \& Gilbert, 2004). The extent of specialization will depend in part on the level of gene flow between pathogen populations and the presence of multiple potential hosts, as these could limit the evolution of specialization (Andreazzi et al., 2017; Parker \& Gilbert, 2004). Novel gene flow across species or strains, however, may promote host jumps and the emergence of new infectious diseases. Hybridization, for example, led to the emergence of Ophistoma novo-ulmi (Dutch elm disease) in Europe (Burdon \& Thrall, 2008; Fisher et al., 2012; Stukenbrock \& McDonald, 2008; Woolhouse, Haydon, \& Antia, 2005).

Our results are consistent with theoretical expectations regarding novel plant-pathogen interactions, and are based on interactions drawn from a broad geographical region while attempting to control for many of the uncertainties and biases common to such datasets (e.g. sampling bias and taxonomically difficult species; Desprez-Loustau et al., 2010). Greater resolution of taxonomically difficult species groups (e.g. species complexes or cryptic species; Crous, Hawksworth, \& Wingfield, 2015) would likely increase estimates of pathogen host range and lead to greater connectance and linkage density, and decreased specialization and modularity in the networks. Since many of these taxonomically difficult species are considered alien to New Zealand (Table S2), this might be more likely to occur in alien pathogens. By removing prominent pathogen species complexes (e.g. Alternaria alternata), commonly misidentified species, and fungi with an uncertain native or alien status, we minimized these effects, but this may have contributed to the low connectance and high modularity and specialization found in our networks. Greater sampling of plant-pathogen interactions would increase the reliability of the network, but we tried to account for sampling biases directly (e.g. including number of records when modelling the number of hosts) or indirectly by comparing the results to randomized matrices, which accounted for network size and the distribution of sampling effort (i.e. link weights), or are relatively unbiased by sampling effort (e.g. $\mathrm{H}_{2}^{\prime}$ ) (Blüthgen et al., 2008; Fründ, McCann, \& Williams, 2016).

\section{5 | CONCLUSIONS}

Plant-pathogen networks are rarely studied, particularly in the context of invasions (Médoc et al., 2017; Vacher et al., 2010), and our study provides key insights into the characteristics of alien pathogens and the structure of novel plant-pathogen networks. Understanding novel plant-pathogen associations in a network context can help elucidate the factors that structure plant-pathogen associations, for 
example by comparing novel and native network structures to test for patterns consistent with evolutionary processes (Andreazzi et al., 2017; Pires \& Guimarães Jr, 2012). These comparisons can also provide insights into the potential impacts of alien pathogen invasions. Because alien pathogens interacted with more native plant hosts than native pathogens did, they could increase the risk of adverse indirect effects, including apparent competition between hosts and pathogen spillover from one host to another, potentially affecting the stability of plant populations and the plant-pathogen network. Research examining not only the presence, but also the virulence of alien pathogens on native plants in the context of network structure could contribute substantially to our understanding of the likely impact of alien pathogens at the community level.

\section{ACKNOWLEDGEMENTS}

We thank Kate Boardman and Ines Schonberger for providing access to data on plant status in New Zealand, and Alison Stewart for assistance in classifying fungal associates as plant pathogens. Research was supported by the Tertiary Education Commission through its Centres of Research Excellence programme. We also thank the reviewers and editor for helpful comments that improved the manuscript.

\section{AUTHORS' CONTRIBUTIONS}

J.L.B., P.E.H. and R.P.D. planned and designed the research. J.A.C., P.R.J., J.L.B. and B.A.S. compiled and processed the data. J.L.B., P.E.H. and R.P.D. analysed the data. J.A.C., P.R.J. and B.A.S. provided expertise for interpretation of the results. J.L.B., P.E.H. and R.P.D. wrote the manuscript and all authors assisted in revising the manuscript.

\section{DATA AVAILABILITY STATEMENT}

Data are publically available through the NZFungi2 database, hosted by Landcare Research: https://nzfungi2.landcareresearch.co.nz/.

\section{ORCID}

Jennifer L. Bufford (iD https://orcid.org/0000-0003-3320-6024

Philip E. Hulme (iD https://orcid.org/0000-0001-5712-0474

Richard P. Duncan iD https://orcid.org/0000-0003-2295-449X

\section{REFERENCES}

Allan Herbarium. (2015). Ngā tipu o Aotearoa - New Zealand plant names database. New Zealand, NZ: Landcare Research.

Almeida-Neto, M., Guimarães, P. R. Jr., Loyota, R. D., \& Ulrich, W. (2008). A consistent metric for nestedness analysis in ecological systems: Reconciling concept and measurements. Oikos, 117, 1227-1239. https://doi.org/10.1111/j.2008.0030-1299.16644.x

Anderson, P. K., Cunningham, A. A., Patel, N. G., Morales, F. J., Epstein, P. R., \& Daszak, P. (2004). Emerging infectious diseases of plants: Pathogen pollution, climate change and agrotechnology drivers. Trends in Ecology \& Evolution, 19(10), 535-544. https://doi. org/10.1016/j.tree.2004.07.021

Andreazzi, C. S., Thompson, J. N., \& Guimarães, P. R. Jr. (2017). Network structure and selection asymmetry drive coevolution in species-rich antagonistic interactions. The American Naturalist, 190(1), 99-115. https://doi.org/10.1086/692110

Barrett, L. G., Encinas-Viso, F., Burdon, J. J., \& Thrall, P. H. (2015). Specialization for resistance in wild host-pathogen interaction networks. Frontiers in Plant Science, 6, 1-13. https://doi.org/10.3389/ fpls.2015.00761

Barrett, L. G., \& Heil, M. (2012). Unifying concepts and mechanisms in the specificity of plant-enemy interactions. Trends in Plant Science, 17(5), 282-292. https://doi.org/10.1016/j.tplants.2012.02.009

Bates, D. M., Maechler, M., Bolker, B. M., \& Walker, S. C. (2014). Ime4: Linear mixed-effects models using eigen and S4.

Bebber, D. P., Holmes, T., \& Gurr, S. J. (2014). The global spread of crop pests and pathogens. Global Ecology and Biogeography, 23(12), 13981407. https://doi.org/10.1111/geb.12214

Bersier, L.-F., Banašek-Richter, C., \& Cattin, M.-F. (2002). Quantitative descriptors of food-web matrices. Ecology, 83(9), 2394-2407. https:// doi.org/10.1890/0012-9658(2002)083[2394:QDOFWM]2.0.CO;2

Blondel, V. D., Guillaume, J.-L., Lambiotte, R., \& Lefebvre, E. (2008). Fast unfolding of communities in large networks. Journal of Statistical Mechanics: Theory and Experiment, 10008(10), 6. https://doi. org/10.1088/1742-5468/2008/10/P10008

Blüthgen, N., Fründ, J., Vázquez, D. P., \& Menzel, F. (2008). What do interaction network metrics tell us about specialization and biological traits. Ecology, 89(12), 3387-3399. https://doi.org/10.1890/07-2121.1

Blüthgen, N., Menzel, F., \& Blüthgen, N. (2006). Measuring specialization in species interaction networks. BMC Ecology, 6, 9. https://doi. org/10.1186/1472-6785-6-9

Bolker, B. M., Brooks, M. E., Clark, C. J., Geange, S. W., Poulsen, J. R., Stevens, M. H. H., \& White, J. S. (2009). Generalized linear mixed models: A practical guide for ecology and evolution. Trends in Ecology and Evolution, 24(3), 127-135. https://doi.org/10.1016/j. tree.2008.10.008

Brown, J. K. M., \& Hovmøller, M. S. (2002). Aerial dispersal of pathogens on the global and continental scales and its impact on plant disease. Science, 297, 537-541. https://doi.org/10.1126/science.1072678

Bufford, J. L., Hulme, P. E., Sikes, B. A., Cooper, J. A., Johnston, P. R., \& Duncan, R. P. (2016). Taxonomic similarity, more than contact opportunity, explains novel plant-pathogen associations between native and alien taxa. New Phytologist, 212(3), 657-667. https://doi. org/10.1111/nph.14077

Burdon, J. J., \& Thrall, P. H. (2008). Pathogen evolution across the agro-ecological interface: Implications for disease management. Evolutionary Applications, 1(1), 57-65. https://doi. org/10.1111/j.1752-4571.2007.00005.x

Burdon, J. J., \& Thrall, P. H. (2013). What have we learned from studies of wild plant-pathogen associations?-the dynamic interplay of time, space and life-history. European Journal of Plant Pathology, 138(3), 417-429. https://doi.org/10.1007/s10658-013-0265-9

Cayuela, L., Granzow-de la Cerda, Í., Albuquerque, F. S., \& Golicher, D. J. (2012). Taxonstand: An R package for species names standardisation in vegetation databases. Methods in Ecology and Evolution, 3(6), 1078-1083. https://doi.org/10.1111/j.2041-210X.2012.00232.x

Chamberlain, S. A., \& Szöcs, E. (2013). Taxize: Taxonomic Search and Retrieval in R, F1000Research, 2(191). https://doi.org/10.12688/ f1000research.2-191.v2

Clauset, A., Newman, M. E. J., \& Moore, C. (2004). Finding community structure in very large networks. Physical Review E, 70, 066111. https ://doi.org/10.1103/PhysRevE.70.066111

Crous, P. W., Hawksworth, D. L., \& Wingfield, M. J. (2015). Identifying and naming plant-pathogenic fungi: Past, present, and future. Annual 
Review of Phytopathology, 53(1), 247-267. https://doi.org/10.1146/ annurev-phyto-080614-120245

Csardi, G., \& Nepusz, T. (2006). The igraph software package for complex network research. InterJournal, Complex Sy, 1695.

de Castro, F., \& Bolker, B. M. (2005a). Mechanisms of disease-induced extinction. Ecology Letters, 8(1), 117-126. https://doi. org/10.1111/j.1461-0248.2004.00693.x

de Castro, F., \& Bolker, B. M. (2005b). Parasite establishment and host extinction in model communities. Oikos, 111, 501-513. http://doi. wiley.com/10.1111/j.1600-0706.2005.14101.x

de Lange, P. J., \& Rolfe, J. R. (2010). New Zealand indigenous vascular plant checklist. Wellington, NZ: New Zealand Plant Conservation Network.

Desprez-Loustau, M.-L., Courtecuisse, R., Robin, C., Husson, C., Moreau, P.-A., Blancard, D., ... Sache, I. (2010). Species diversity and drivers of spread of alien fungi (sensu lato) in Europe with a particular focus on France. Biological Invasions, 12(1), 157-172. https://doi.org/10.1007/ s10530-009-9439-y

Desprez-Loustau, M.-L., Robin, C., Buee, M., Courtecuisse, R., Garbaye, J., Suffert, F., ... Rizzo, D. (2007). The fungal dimension of biological invasions. Trends in Ecology and Evolution, 22(9), 472-480. https://doi. org/10.1016/j.tree.2007.04.005

Dickie, I. A., Bufford, J. L., Cobb, R. C., Desprez-Loustau, M.-L., Grelet, G., Hulme, P. E., ... Williams, N. M. (2017). The emerging science of linked plant-fungal invasions. New Phytologist, 215(4), 1314-1332. https://doi.org/10.1111/nph.14657

Dickie, I. A., Cooper, J. A., Bufford, J. L., Hulme, P. E., \& Bates, S. T. (2017). Loss of functional diversity and network modularity in introduced plant-fungal symbioses. AoB PLANTS, 9(1), plw084. https://doi. org/10.1093/aobpla/plw084

Dormann, C. F., Fruend, J., Blüthgen, N., \& Gruber, B. (2009). Indices, graphs and null models: Analyzing bipartite ecological networks. The Open Ecology Journal, 2, 7-24. https://doi.org/10.2174/1874213000 902010007

Dormann, C. F., Gruber, B., \& Fruend, J. (2008). Introducing the bipartite package: Analysing ecological networks. R News, 8(2), 8-11.

Elias, M., Fontaine, C., \& van Veen, F. J. F. (2013). Evolutionary history and ecological processes shape a local multilevel antagonistic network. Current Biology, 23(14), 1355-1359. https://doi.org/10.1016/j. cub.2013.05.066

Fisher, M. C., Henk, D. A., Briggs, C. J., Brownstein, J. S., Madoff, L. C., McCraw, S. L., \& Gurr, S. J. (2012). Emerging fungal threats to animal, plant and ecosystem health. Nature, 484, 186-194. https://doi. org/10.1038/nature10947

Flory, S. L., \& Clay, K. (2013). Pathogen accumulation and long-term dynamics of plant invasions. Journal of Ecology, 101(3), 607-613. https ://doi.org/10.1111/1365-2745.12078

Fründ, J., McCann, K. S., \& Williams, N. M. (2016). Sampling bias is a challenge for quantifying specialization and network structure: Lessons from a quantitative niche model. Oikos, 125(4), 502-513. https://doi. org/10.1111/oik.02256

Gadgil, P. D. (2005). Fungi on trees and shrubs in New Zealand. Fungi of New Zealand Volume 4. Fungal Diversity Research Series, 16, 1-437.

Gilbert, G. S., Magarey, R., Suiter, K., \& Webb, C. O. (2012). Evolutionary tools for phytosanitary risk analysis: Phylogenetic signal as a predictor of host range of plant pests and pathogens. Evolutionary Applications, 5(8), 869-878. https://doi. org/10.1111/j.1752-4571.2012.00265.x

Gilbert, G. S., \& Parker, I. M. (2010). Rapid evolution in a plant-pathogen interaction and the consequences for introduced host species. Evolutionary Applications, 3(2), 144-156. https://doi. org/10.1111/j.1752-4571.2009.00107.x

Howell, C. (2008). Consolidated list of environmental weeds in New Zealand. DOC Research \& Development Series, 292, 42.

Hui, C., Richardson, D. M., Pyšek, P., Le Roux, J. J., Kučera, T., \& Jarošík, V. (2013). Increasing functional modularity with residence time in the co-distribution of native and introduced vascular plants. Nature Communications, 4, 2454. https://doi.org/10.1038/ncomms3454

Johnston, P. R., Weir, B. S., \& Cooper, J. A. (2017). Open data on fungi and bacterial plant pathogens in New Zealand. Mycology, 8(2), 59-66. https://doi.org/10.1080/21501203.2016.1278409

Kew Royal Botanical Gardens. (2012). HerbIMI. Retrieved from http://www.herbimi.info/; Accessed date: August 26, 2012.

Landcare Research. (2014). New Zealand fungi and bacteria (NZFUNGI). Retrieved from http://nzfungi2.landcareresearch.co.nz/; Accessed date: August 4, 2014.

Lewinsohn, T. M., Inácio Prado, P., Jordano, P., Bascompte, J., \& Olesen, J. M. (2006). Structure in plant-animal interaction assemblages. Oikos, 113, 174-184. https://doi.org/10.1111/j.0030-1299.2006.14583.x

Lopezaraiza-Mikel, M. E., Hayes, R. B., Whalley, M. R., \& Memmott, J. (2007). The impact of an alien plant on a native plant-pollinator network: An experimental approach. Ecology Letters, 10(7), 539-550. https://doi.org/10.1111/j.1461-0248.2007.01055.x

McKenzie, E. (1998). Rust fungi of New Zealand - an introduction, and list of recorded species. New Zealand Journal of Botany, 36(2), 233-271. https://doi.org/10.1080/0028825X.1998.9512564

Médoc, V., Firmat, C., Sheath, D. J., Pegg, J., Andreou, D., \& Britton, J. R. (2017). Parasites and biological invasions. Advances in Ecological Research, 57, 1-54. https://doi.org/10.1016/bs.aecr.2016.10.003

Morris, R. J., Gripenberg, S., Lewis, O. T., \& Roslin, T. (2014). Antagonistic interaction networks are structured independently of latitude and host guild. Ecology Letters, 17(3), 340-349. https://doi.org/10.1111/ ele.12235

Nakagawa, S., \& Schielzeth, H. (2013). A general and simple method for obtaining $R^{2}$ from generalized linear mixed-effects models. Methods in Ecology and Evolution, 4(2), 133-142. https://doi. org/10.1111/j.2041-210x.2012.00261.x

Nogales, M., Heleno, R., Rumeu, B., González-Castro, A., Traveset, A., Vargas, P., \& Olesen, J. M. (2016). Seed-dispersal networks on the Canaries and the Galápagos archipelagos: Interaction modules as biogeographical entities. Global Ecology and Biogeography, 25(7), 912-922. https://doi.org/10.1111/geb.12315

Oksanen, J., Blanchet, F. G., Kindt, R., Legendre, P., Minchin, P. R., O'Hara, R. B., Wagner, H. H. (2013). vegan: community ecology package.

Parker, I. M., \& Gilbert, G. S. (2004). The evolutionary ecology of novel plant-pathogen interactions. Annual Review of Ecology, Evolution, and Systematics, 35(2004), 675-700. https://doi.org/10.1146/annur ev.ecolsys.35.011802.132339

Parker, I. M., Saunders, M., Bontrager, M., Weitz, A. P., Hendricks, R., Magarey, R., ... Gilbert, G. S. (2015). Phylogenetic structure and host abundance drive disease pressure in communities. Nature, 520(7548), 542-544. https://doi.org/10.1038/nature14372

Philibert, A., Desprez-Loustau, M.-L., Fabre, B., Frey, P., Halkett, F., Husson, C., ... Makowski, D. (2011). Predicting invasion success of forest pathogenic fungi from species traits. Journal of Applied Ecology, 48(6), 1381-1390. https://doi.org/10.1111/j.1365-2664.2011.02039.x

Pires, M. M., \& Guimarães, P. R. Jr. (2012). Interaction intimacy organizes networks of antagonistic interactions in different ways. Journal of the Royal Society Interface, 10, 20120649. https://doi.org/10.1098/ rsif.2012.0649

Power, A. G., \& Mitchell, C. E. (2004). Pathogen spillover in disease epidemics. The American Naturalist, 164(S5), S79-S89. https://doi. org $/ 10.1086 / 424610$

Quinn, G. P., \& Keough, M. J. (2002). Experimental design and data analysis for biologists. New York, NY: Cambridge University Press.

R Core Team. (2017). R: A language environment for statistical computing. Vienna, Austria: R Foundation for Statistical Computing.

Russo, L., Memmott, J., Montoya, D., Shea, K., \& Buckley, Y. M. (2014). Patterns of introduced species interactions affect multiple aspects of network structure in plant - pollinator communities. Ecology, 95(10), 2953-2963. https://doi.org/10.1890/13-2229.1 
Sikes, B. A., Bufford, J. L., Hulme, P. E., Cooper, J. A., Johnston, P. R., \& Duncan, R. P. (2018). Import volumes and biosecurity interventions shape the arrival rate of fungal pathogens. PLOS Biology, 16(5), e2006025. https://doi.org/10.1371/journal.pbio.2006025

Smith, K. F., Sax, D. F., \& Lafferty, K. D. (2006). Evidence for the role of infectious disease in species extinction and endangerment. Conservation Biology, 20(5), 1349-1357. https://doi. org/10.1111/j.1523-1739.2006.00524.x

Stouffer, D. B., Cirtwill, A. R., \& Bascompte, J. (2014). How exotic plants integrate into pollination networks. Journal of Ecology, 102(6), 14421450. https://doi.org/10.1111/1365-2745.12310

Stukenbrock, E. H., \& McDonald, B. A. (2008). The origins of plant pathogens in agro-ecosystems. Annual Review of Phytopathology, 46(1), 75-100. https://doi.org/10.1146/annurev.phyto.010708.154114

Thébault, E., \& Fontaine, C. (2010). Stability of ecological communities and the architecture of mutualistic and trophic networks. Science, 329(5993), 853-856. https://doi.org/10.1126/science.118 8321

Vacher, C., Daudin, J.-J., Piou, D., \& Desprez-Loustau, M.-L. (2010). Ecological integration of alien species into a tree-parasitic fungus network. Biological Invasions, 12(9), 3249-3259. https://doi. org/10.1007/s10530-010-9719-6

Vacher, C., Piou, D., \& Desprez-Loustau, M.-L. (2008). Architecture of an antagonistic tree/fungus network: The asymmetric influence of past evolutionary history. PLoS ONE, 3(3), e1740. https://doi. org/10.1371/journal.pone.0001740

Valdovinos, F. S., Ramos-Jiliberto, R., Flores, J. D., Espinoza, C., \& López, G. (2009). Structure and dynamics of pollination networks: The role of alien plants. Oikos, 118(8), 1190-1200. https://doi. org/10.1111/j.1600-0706.2009.17364.x
Viljanen-Rollinson, S., \& Cromey, M. (2002). Pathways of entry and spread of rust pathogens: Implications for New Zealand's biosecurity. New Zealand Plant Protection, 48(February), 42-48.

Webb, C. O., \& Donoghue, M. J. (2005). Phylomatic: Tree assembly for applied phylogenetics. Molecular Ecology Notes, 5(1), 181-183. https ://doi.org/10.1111/j.1471-8286.2004.00829.x

Woolhouse, M. E. J., Haydon, D. T., \& Antia, R. (2005). Emerging pathogens: The epidemiology and evolution of species jumps. Trends in Ecology and Evolution, 20(5), 238-244. https://doi.org/10.1016/j.tree.2005.02.009

Young, H. S., Parker, I. M., Gilbert, G. S., Guerra, A. S., \& Nunn, C. L. (2017). Introduced species, disease ecology, and biodiversity-disease relationships. Trends in Ecology and Evolution, 32(1), 41-54. https ://doi.org/10.1016/j.tree.2016.09.008

\section{SUPPORTING INFORMATION}

Additional supporting information may be found online in the Supporting Information section at the end of the article.

How to cite this article: Bufford JL, Hulme PE, Sikes BA, Cooper JA, Johnston PR, Duncan RP. Novel interactions between alien pathogens and native plants increase plant-pathogen network connectance and decrease specialization. J Ecol. 2020;108:750-760. https://doi. org/10.1111/1365-2745.13293 